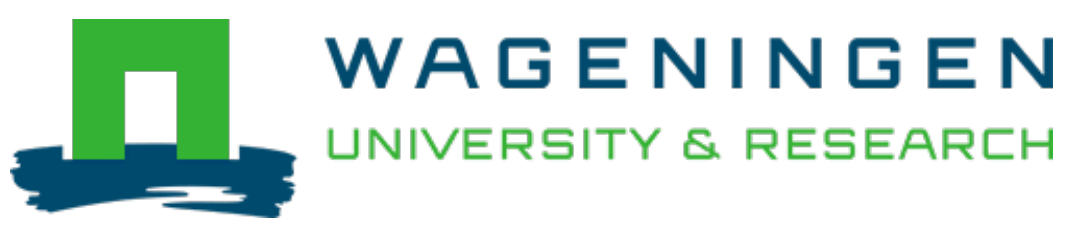

\title{
Season-specific carryover of early life associations in a monogamous bird species
}

Animal Behaviour

Kurvers, Ralf H.J.M.; Prox, Lea; Farine, Damien R.; Jongeling, Coretta; Snijders, Lysanne

https://doi.org/10.1016/j.anbehav.2020.03.016

This article is made publicly available in the institutional repository of Wageningen University and Research, under the terms of article $25 \mathrm{fa}$ of the Dutch Copyright Act, also known as the Amendment Taverne. This has been done with explicit consent by the author.

Article $25 \mathrm{fa}$ states that the author of a short scientific work funded either wholly or partially by Dutch public funds is entitled to make that work publicly available for no consideration following a reasonable period of time after the work was first published, provided that clear reference is made to the source of the first publication of the work.

This publication is distributed under The Association of Universities in the Netherlands (VSNU) 'Article $25 \mathrm{fa}$

implementation' project. In this project research outputs of researchers employed by Dutch Universities that comply with the legal requirements of Article $25 \mathrm{fa}$ of the Dutch Copyright Act are distributed online and free of cost or other barriers in institutional repositories. Research outputs are distributed six months after their first online publication in the original published version and with proper attribution to the source of the original publication.

You are permitted to download and use the publication for personal purposes. All rights remain with the author(s) and / or copyright owner(s) of this work. Any use of the publication or parts of it other than authorised under article $25 \mathrm{fa}$ of the Dutch Copyright act is prohibited. Wageningen University \& Research and the author(s) of this publication shall not be held responsible or liable for any damages resulting from your (re)use of this publication.

For questions regarding the public availability of this article please contact openscience.library@,wur.nl 


\title{
Season-specific carryover of early life associations in a monogamous bird species
}

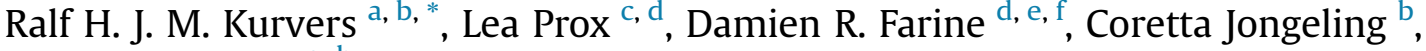 \\ Lysanne Snijders ${ }^{g, h}$ \\ ${ }^{a}$ Center for Adaptive Rationality, Max Planck Institute for Human Development, Berlin, Germany \\ ${ }^{\mathrm{b}}$ Wildife Ecology and Conservation Group, Wageningen University and Research, Wageningen, the Netherlands \\ ${ }^{\mathrm{c}}$ Behavioral Ecology \& Sociobiology Unit, German Primate Center, Göttingen, Germany \\ ${ }^{\mathrm{d}}$ Department of Biology, University of Konstanz, Konstanz, Germany \\ e Department of Collective Behavior, Max Planck Institute of Animal Behavior, Konstanz, Germany \\ ${ }^{\mathrm{f}}$ Centre for the Advanced Study of Collective Behaviour, University of Konstanz, Konstanz, Germany \\ ${ }^{g}$ Department of Evolutionary Ecology, Leibniz Institute for Zoo and Wildlife Research, Berlin, Germany \\ ${ }^{\mathrm{h}}$ Behavioural Ecology Group, Wageningen University and Research, Wageningen, the Netherlands
}

\section{A R T I C L E I N F O}

\section{Article history:}

Received 7 November 2019

Initial acceptance 9 January 2020

Final acceptance 3 March 2020

MS number 19-00741

\section{Keywords:}

aggression

early life

familiarity

genetic relatedness

monogamous

pair formation

social associations

social relationships
Social relationships can have important fitness consequences. Although there is increasing evidence that social relationships carry over across contexts, few studies have investigated whether relationships formed early in life are carried over to adulthood. For example, juveniles of monogamous species go through a major life history stage transition, pair formation, during which the pair bond becomes a central unit of the social organization. At present, it remains unclear whether pair members retain their early life relationships after pair formation. We investigated whether same-sex associations formed early in life carry over into adulthood and whether carryover was dependent on season, in a monogamous species. We also investigated the role of familiarity, genetic relatedness and aggression on the perseverance of social associations. We studied the social structure before and after pair formation in captive barnacle geese, Branta leucopsis, a highly social, long-lived, monogamous species. We constructed association networks of groups of geese before pair formation, during the subsequent breeding season and in the following wintering season. Next, we studied how these associations carried over during seasonal changes. We found that early life associations in females were lost during the breeding season but resurfaced during the subsequent wintering season. In males, the early life associations persisted across both seasons. Association persistence was not mediated by genetic relatedness or familiarity. The high level of aggressiveness of males, but not females, in the breeding season suggests that males may have played a key role in shaping both their own social environment and that of their partners. We show that early life social relationships can be maintained well into later life. Such relationships can be sustained even if they are temporarily disrupted, for example due to reproductive behaviour. Our findings therefore highlight that the early life social environment can have lifelong consequences for individuals' social environment.

(c) 2020 The Association for the Study of Animal Behaviour. Published by Elsevier Ltd. All rights reserved.
The adaptive nature of sociality is a long-standing topic in ecology and evolution (Alexander, 1974; Krause \& Ruxton, 2002), particularly the potential costs and benefits of maintaining stable social relationships. Repeated social interactions between the same individuals have, for example, been linked to faster predator evasion responses and increased foraging success (Carter,

\footnotetext{
* Correspondence: R.H.J.M. Kurvers, Center for Adaptive Rationality, Max Planck Institute for Human Development, Lentzeallee 94, 14195, Berlin, Germany.

E-mail address: kurvers@mpib-berlin.mpg.de (R. H. J. M. Kurvers).
}

Macdonald, Thomson, \& Goldizen, 2009; Griffiths, Brockmark, Höjesjö, \& Johnsson, 2004), and can, ultimately, affect fitness (Beletsky \& Orians, 1989; Cameron, Setsaas, \& Linklater, 2009; Kohn, 2017; Silk, 2007; Silk et al., 2009, 2010).

There is increasing evidence that social relationships carry over across time, place and context. Shizuka et al. (2014) showed that golden-crowned sparrows, Zonotrichia atricapilla, that flocked together in one winter flocked together in the subsequent winter more often than expected based on the degree of home range overlap. Roosting associations in Bechstein's bats, Myotis 
bechsteinii, and Natterer's bats, Myotis nattereri, were found to remain stable across several years despite high fission-fusion dynamics (Kerth, Perony, \& Schweitzer, 2011; Zeus, Reusch, \& Kerth, 2018). Stanley, Mettke-Hofmann, Hager, and Shultz (2018) showed that, despite seasonal fluctuations in gregariousness and overall weak social associations, semiferal ponies, Equus caballus, maintained stable association preferences over 3 years. Finally, Firth and Sheldon (2016) showed that winter social associations of great tits, Parus major, carried over into their subsequent breeding season, as individuals bred nearer to those they were most associated with during winter. Despite evidence that social associations between individuals can persist across time and context, it is still largely unknown when these relationships are formed in the first place.

Experiences in early life are known to regularly carry over to adulthood, influencing survival and reproductive performance (Lindström, 1999). Early life social conditions are generally known to have long-lasting effects (Langenhof \& Komdeur, 2018; Leris \& Reader, 2016; Stanton \& Mann, 2012; Szipl, Depenau, Kotrschal, Hemetsberger, \& Frigerio, 2019). Despite the likely significance of the early life period for the formation of social relationships, only a few studies have tracked the social associations of the same individuals from their early life into adulthood (e.g. Carter, Brand, Carter, Shorrocks, \& Goldizen, 2013; Linklater \& Cameron, 2009; Mitani, 2009), and almost exclusively in mammals (but see Frigerio, Weiss, \& Kotrschal, 2001 for long-term associations between female siblings in geese). As they mature, individuals of many taxa go through major life history transitions, such as dispersal (Blumstein, Wey, \& Tang, 2009; Linklater \& Cameron, 2009) and pair formation (Kurvers et al., 2013). These transitions will strongly impact the structure of an individual's social environment, but perturbations in the social environment do not necessarily impact the stability of already established relationships (e.g. Kerth et al., 2011). It remains an open question whether a life history transition such as pair formation will cause preferred associations formed in early life to disappear or whether these may persist into adulthood.

Here, we examined the social structure of barnacle geese, Branta leucopsis, a highly social species, before and after pair formation, to study the persistence (or disappearance) of early life same-sex associations after a major life history transition: pair formation. Barnacle geese are long-lived monogamous birds, which generally find a partner at 2-3 years of age (Choudhury \& Black, 1994). Barnacle geese are very selective in choosing a mate; they sample one to six potential mates in so-called 'trial liaisons' before settling with a permanent partner (Choudhury \& Black, 1993; van der Jeugd \& Blaakmeer, 2001). The pair bond is extremely strong and pair members generally stay close to each other and remain together until one of them dies (Black, 2001; Owen, Black, \& Liber, 1988). Pairs with a longer pair bond have higher reproductive success than pairs with a shorter pair bond (Black, 2001). Pair formation is thus a crucial step in the life history of geese. Here we took advantage of controlled experiments to study how pair formation impacted same-sex foraging associations formed early in life, allowing us to circumvent problems with missing individuals in naturalistic data. We followed a captive population of barnacle geese over several years, quantifying the dyadic association strength between individual geese before and after pair formation. To study mediating factors underlying the potential persistence of these dyadic associations, we quantified the degree of familiarity and genetic relatedness in the population, as well as individuals' aggressive interactions. We focused on the persistence of same-sex associations because, in comparison to intersex associations, these relationships are less well studied in monogamous social species, but may have important adaptive benefits, for example stress reduction
(Sachser, Dürschlag, \& Hirzel, 1998), especially in competitive contexts such as foraging.

In the wild, barnacle geese, like many migratory waterfowl, show high site fidelity to their breeding, wintering and staging areas (Percival, 1991; Robertson \& Cooke, 1999), creating opportunities for long-term maintenance of social relationships established early in life. Both sexes show natal philopatry, although females have substantially higher levels of natal philopatry than males (van der Jeugd, 2001; van der Jeugd, van der Veen, \& Larsson, 2002). The extent to which individuals maintain nonsexual relationships across seasons is not well understood, partly because of the challenges of following individuals across space and time. van der Jeugd et al. (2002) showed that during breeding, female, but not male, barnacle geese nested closer to siblings than expected by chance. This occurred not only when the female siblings bred on the same island as their parents, but also when they nested on a different island. Moreover, this relationship was only observed for siblings hatched in the same year. Similar sex-specific patterns have been observed in terms of resting proximity in semiferal greylag geese, Anser anser, in winter (Frigerio et al., 2001). Given these observations and females being the more philopatric sex, we predicted that females would be more likely to maintain their early life relationships than males after mating.

We constructed association matrices from foraging observations collected during the breeding and wintering seasons. Geese are generally more gregarious during the wintering season (Black, Prop, \& Larsson, 2014; Szipl et al., 2019) but more aggressive and territorial during the breeding season (Owen \& Wells, 1979). We therefore predicted that associations with early life companions after pair formation would be stronger in the wintering than the breeding season. Finally, based on the expected direct and indirect adaptive benefits of associating with kin, for example by providing and receiving social support (Black \& Owen, 1989; Raveling, Sedinger, \& Johnson, 2000; Scheiber et al., 2005, 2009), we predicted that genetic relatedness would positively impact the strength of the associations. Similarly, based on the expected benefits of reduced aggression between familiar individuals (i.e. 'dear-enemy effect'; van der Jeugd, 2001; Ydenberg, Giraldeau, \& Falls, 1988), we predicted that long-term familiarity would positively influence dyadic foraging association strength.

\section{METHODS}

\section{Study Subjects}

In late 2007 we obtained two mixed-sex groups of barnacle geese (see Fig. 1 for study timeline, and Kurvers et al., 2013 for more details). The two groups consisted of 23 (eight females, 15 males) and 21 (13 females, eight males) individuals, respectively. The groups were housed in separate outdoor aviaries $(12 \times 15 \mathrm{~m})$ at the Netherlands Institute of Ecology (NIOO) in Heteren, The Netherlands. Groups were visually, but not acoustically, isolated from each other. The aviaries consisted of bare soil with a large pond $(6 \times 1 \mathrm{~m})$ with running water for drinking and bathing. Birds received ad libitum food consisting of a mixture of grains and pellets occasionally supplemented with grass. Most individuals (40 of 44) were hatched in 2007 and were thus approximately 5 months old upon arrival. All birds were captive hatched, wing clipped and (upon arrival) fitted with uniquely coded white leg rings for identification. Birds from the two groups had different origins, implying that birds within (but not between) groups could have a high genetic relatedness (see below). Birds within a group will henceforth be referred to as 'familiar' individuals, and birds between groups as 'unfamiliar'. Geese lived for approximately 1.5 


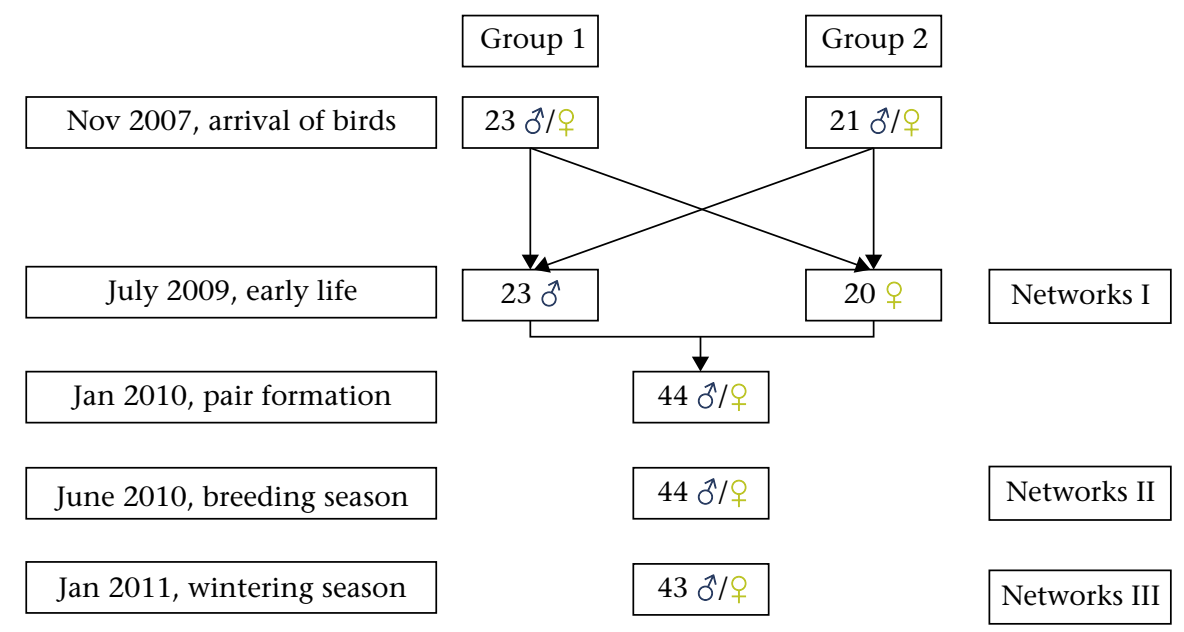

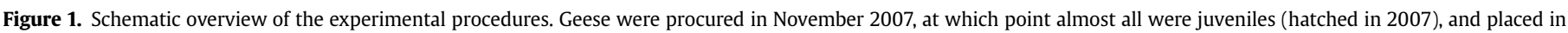

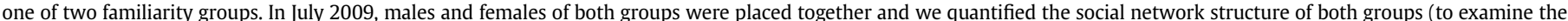

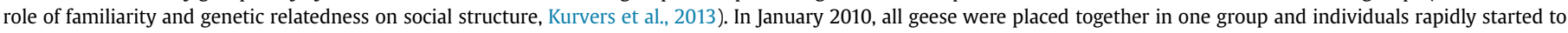

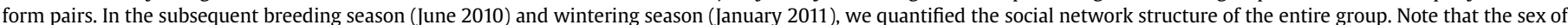

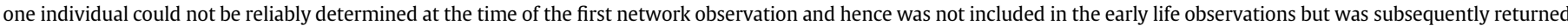

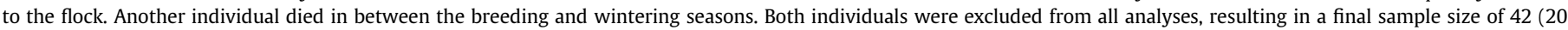
females, 22 males); however, for completeness they are included in the numbers in this overview figure.

years in these familiarity groups before the start of the social network observations (see below).

\section{Genetic Relatedness}

We determined the genetic relatedness between each pair of individuals using a high-resolution 374 single-nucleotide polymorphism (SNP) marker set, developed for the barnacle goose (Jonker et al., 2012). We took a small blood sample $( \pm 1 \mathrm{ml})$ from each bird from the brachial vein and preserved it in ethanol. Entire genomic DNA was isolated using the Gentra Systems Puregene DNA purification kit (Qiagen, Venlo, The Netherlands). Genotyping was conducted with Vera Code assays on an Illumina BeadXpress (Illumina, San Diego, CA, U.S.A.; described in Kraus et al., 2011). We calculated the pairwise genetic relatedness $(r)$ using the program Coancestry (version 1, Wang, 2011). To determine which relatedness estimator best fitted our data, we used the empirical SNP allele frequencies of our population and simulated 500 dyads of geese of varying relatedness coefficients. Meeting real conditions as closely as possible, we simulated mainly unrelated dyads $(N=430)$ but also dyads of close familial relationships, namely 30 full-sib dyads $(r=0.5), 10$ half-sib dyads $(r=0.25)$ and 30 first-cousin dyads $(r=0.125)$. Based on this simulation, we found that the maximumlikelihood estimator of Milligan (2003) performed best and used it for the final estimation of $r$. This produced a strong correlation with expected values of $r\left(r^{2}=0.9\right.$; analysis of the simulated data set carried out with default settings). Subsequently, all pairwise relatedness values of the experimental geese were obtained from Coancestry with standard settings (see Kurvers et al., 2013 for more details).

\section{Early Life Observations}

After the geese had been in their respective familiarity groups for approximately 1.5 years, and prior to any pair formation, we separated them into two single-sex groups (June 2009; Fig. 1) to study the factors shaping intrasexual social association preferences while avoiding additional 'noise' caused by intersexual trial liaisons (van der Jeugd \& Blaakmeer, 2001). Moreover, by separating individuals into single-sex groups, we could control the timing of pair formation and keep this comparable and tractable for all subjects. Geese were sexed by visual inspection of sexual organs in the cloaca. As its sex could not be reliably determined at this time, one individual was not included in the early life observations but joined the flock after these observations finished. We excluded it from all analyses. Association observations were conducted in the home aviaries during foraging. These foraging associations were studied on five grass patches ( $40 \times 20 \mathrm{~cm}, 1.5 \mathrm{~m}$ apart) which were replaced twice a day to avoid depletion. Other food sources were removed during the observations.

Each single-sex group was observed (0900-1300 hours) for 15 days (females: 22 June-12 July 2009; males: 13-30 July 2009). The presence of all individuals on the patches was recorded every $4 \mathrm{~min}$. This interval was longer than the mixing time among individuals (i.e. the time individuals need to change association partners), to ensure independence of observations (Croft, James, \& Krause, 2008). Associations at feeding patches was rarely the same in consecutive records (females: $5.9 \%$; males: $7.9 \%$ ). Observations were occasionally interrupted for $10 \mathrm{~min}$ in the event of an external disturbance. Since patch size $(40 \times 20 \mathrm{~cm})$ and group size (mean females $=1.9$, range $1-5$; mean males $=2.0$, range $1-5$; see Results) were small, we assumed that animals grazing on the same patch during a sampling period were associating (a.k.a. gambit of the group, Franks, Ruxton, \& James, 2010; Whitehead, 2008).

The results of the foraging associations before pair formation are reported in Kurvers et al. (2013). In brief, in both sexes, familiarity and genetic relatedness predicted association strength, whereas boldness and dominance did not. Therefore, we focus here on the role of familiarity and genetic relatedness in governing the stability of long-term associations.

\section{Breeding and Wintering Observations}

Geese remained in the single-sex groups for 6 months and were then placed together in one group (January 2010; Fig. 1). By then, most geese were 2.5 years of age, approximating the average age of final pair formation in barnacle geese (Choudhury \& Black, 1994; van der Jeugd \& Blaakmeer, 2001). Pair formation started rapidly, 
and most geese quickly formed a stable pair bond. Before starting the first association observations after pair formation, 37 (of 44) geese had formed stable pair bonds. In total, geese formed 12 pairs (11 male-female pairs and one male-male pair), four triplets (three geese continuously moving together as one unit without any aggression; two triplets consisted of two females and one male and two of one female and two males) and seven geese (three males, four females) remained unpaired. The occurrence of triplets has also been observed in the wild, with a third party joining a pair between 10 months and 4 years; however, incidence in the field was lower (Black, Choudhury, \& Owen, 1996). As reported in Kurvers et al. (2013) genetic relatedness did not play a role in mate choice, whereas geese actively selected against familiarity in selecting a mate. After the geese formed pair relationships, and during their first breeding season, we again conducted observations of foraging associations. We placed 10 grass patches $(40 \times 40 \mathrm{~cm})$ in the aviary. Observations were conducted for 5 weeks (31 May-2 July 2010, 25 observation days) in two $2 \mathrm{~h}$ blocks per day (0800-1300 hours.) following the same observation protocol described above. During the breeding season, many of the paired individuals started building nests and laying eggs. We regularly checked all nests and removed any eggs to avoid the hatching of goslings.

To study the stability of associations across seasons, we repeated the observations of foraging associations 6 months later, during the wintering season, following the same protocol (17 December 2010-4 February 2011, 13 observation days). Comparing the pair status of all geese between the breeding and wintering seasons, we observed that all but one pair relationships remained the same; the pair relationship that changed was the male-male pair. This reflects the strong and long-lasting pair bonds in barnacle geese, which generally stay together until one of the pair members dies (Black, 2001). One individual died in between the breeding and wintering observations. To facilitate comparison across seasons, we removed this individual from all analyses. The final sample size was thus 42 individuals (20 females, 22 males).

\section{Agonistic Interactions}

During all three observation periods (early life, breeding, wintering), we collected data on agonistic interactions to study the role of aggression on the stability of early life associations. In between scoring the presence of individuals on the patches, we scored the winner and loser of agonistic interactions, defined as a direct confrontation between two geese and ranging from threats with lowered head and neck to active chases with flapping wings. In the early life observations, we identified 1429 interactions in the female group and 2619 interactions in the male group. We then identified 3411 and 786 interactions during the subsequent breeding and wintering periods, respectively.

\section{Statistical Analyses}

\section{Stability of early life connections}

We used social network analysis to investigate carryover effects of dyadic associations between seasons. Within the networks, nodes represent individuals and are connected by edges that represent associations. The edge weight varied with dyadic association strength. From the observation data, we thus generated undirected weighted networks (i.e. networks based on associations without initiators or receivers) for each of the three periods (early life, breeding season and wintering season). Edge weights in the networks were calculated using the simple ratio index (SRI) as an association measure using the 'asnipe' package (Farine, 2013) in $R$ (v. 3.4.4). The SRI indicates the probability of observing two individuals in association with each other given that one was observed. Values range from 0 (two individuals were never observed together) to 1 (two individuals were always observed together). The SRI is considered an effective measure of dyadic association strength provided there are no large sampling biases (Farine \& Whitehead, 2015; Ginsberg \& Young, 1992; Hoppitt \& Farine, 2018). Since all observations were performed within aviaries in which all individuals feeding on all patches could be easily observed, we did not expect a strong sampling bias.

We first analysed whether early life associations (within the same sex) were maintained after pair formation, i.e. during the subsequent breeding and wintering seasons. Within each sex, we performed Mantel tests using the built-in node permutation test from the 'vegan' library Mantel test function, running 50000 permutations and using Spearman correlation (Oksanen et al., 2019), to compare dyads' association strength between (1) early life and breeding season and (2) early life and wintering season. We started with a separate matrix for each sex for the early life associations, one matrix (containing both sexes) for the breeding season and one matrix for the wintering season. To compare the matrix correlation for females (/males), we therefore first subset all females (/males) from the breeding and wintering matrix, constructing single-sex matrices. To confirm that our results were not mainly driven by the associations of the unpaired individuals (as we were primarily interested in the possible continuation of associations after pair formation), we repeated these analyses after further excluding associations between the unpaired individuals. To investigate whether our results were driven by a few strong associations, we also repeated this analysis while excluding all associations with an SRI value higher than 0.1 .

\section{Genetic relatedness and familiarity}

To investigate which factors might underlie a possible continuation of associations after pair formation, we studied the effect of genetic relatedness and familiarity on dyadic association strength during the breeding and wintering seasons. We tested the effect of familiarity and relatedness using multiple regression quadratic assignment procedures (MRQAP; Krackhardt, 1988) using the mrqap.dsp function in the $\mathrm{R}$ package asnipe (Farine, 2013). With this procedure, the association matrix was first regressed against two matrices, one with data on relatedness and one on familiarity. We used a version of the function allowing us to combine the mrqap.dsp model with prenetwork permutations (Farine, 2017). Specifically, we generated 1000 random networks by reorganizing the observations of individuals in the original group-by-individual matrices following the method first described by Bejder, Fletcher, and Brager (1998). We then compared the resulting distribution of coefficient values from these permuted networks to the coefficient value generated from the original observation data to obtain $P$ values. Further, because our random distributions were not centred on 0 (see Farine, 2017), we rescaled measures to an effect size by taking the difference between the observed coefficient values and the mean of the corresponding distribution of coefficient values based on the permutated networks. We performed the MRQAP separately for each season and sex.

\section{Patch visits and aggression}

As we found sex differences in the continuation of early life associations (see below), we investigated the role of patch visit rates and aggression as potential underlying mechanisms. For each individual, for each period, we calculated the mean number of patch visits/h. We then used a Mann-Whitney $U$ test to determine whether the sexes differed in their patch visit rates in each of the three seasons. Similarly, for each individual and for each season, we determined the mean number of aggressive interactions initiated/h 
and tested whether the sexes differed in their likelihood of displaying aggression in each of the three seasons.

Ethical Note. The animal ethical committee of both the Royal Netherlands Academy of Arts and Sciences (KNAW) and the Wageningen University approved all experiments [protocol numbers: 2010008.b (blood sampling)]. Geese were obtained from a waterfowl breeding farm (Kooy and Sons, 't Zand, the Netherlands) and returned there after the experiments had finished.

\section{RESULTS}

\section{Effects of Sex and Season}

We quantified the foraging association networks for each of the three observation periods (i.e. early life, breeding season and wintering season; see Fig. 2), and compared the strength of the dyadic associations that were formed early in life to those in subsequent seasons. We found that a female's dyadic association strengths from early life (i.e. prior to pair formation) were not significantly correlated with its dyadic association strengths to the same pool of individuals (i.e. other females) in the subsequent breeding season $(r=0.04, P=0.32$; Fig. 3a). A female's early life dyadic association strengths were, however, significantly correlated with its dyadic association strengths in the subsequent wintering season $(r=0.18, P=0.019$; Fig. $3 \mathrm{~b})$. A male's early life dyadic association strengths were significantly correlated with its dyadic association strengths to other males in both the subsequent breeding ( $r=0.26, P=0.002$; Fig. 3c) and the following wintering season $(r=0.31, P=0.002$; Fig. $3 \mathrm{~d})$.

When excluding the associations among individuals that remained unpaired (seven of 42 ; but maintaining the associations between paired and unpaired individuals), we obtained similar results (females: early life versus breeding: $r=0.00, P=0.49$; early life versus wintering: $r=0.19, P=0.018$; males: early life versus breeding: $r=0.26, P=0.003$; early life versus wintering: $r=0.31$, $P=0.003$ ).

When excluding all dyadic associations with an SRI value above 0.1 (which excluded 38 associations for females (7\% of all associations) and 26 for males (5\%)), we, again, obtained similar results (females: early life versus breeding: $r=0.00, P=0.52$; early life versus wintering: $r=0.18, P=0.022$; males: early life versus breeding: $r=0.23, P=0.004$; early life versus wintering: $r=0.34$, $P=0.002$ ).

\section{Genetic Relatedness and Familiarity}

In females, there was no effect of genetic relatedness or familiarity on dyadic association strength in the breeding season (effect sizes: genetic relatedness: -0.00006 ; familiarity: 0.0001 ) or in the wintering season (genetic relatedness: 0.0016; familiarity: 0.0001 ). Likewise, for males, we found no effect of genetic relatedness or familiarity on dyadic association strength in the breeding season (genetic relatedness: -0.00035; familiarity: -0.00006 ) or in the wintering season (genetic relatedness: 0.0002; familiarity:
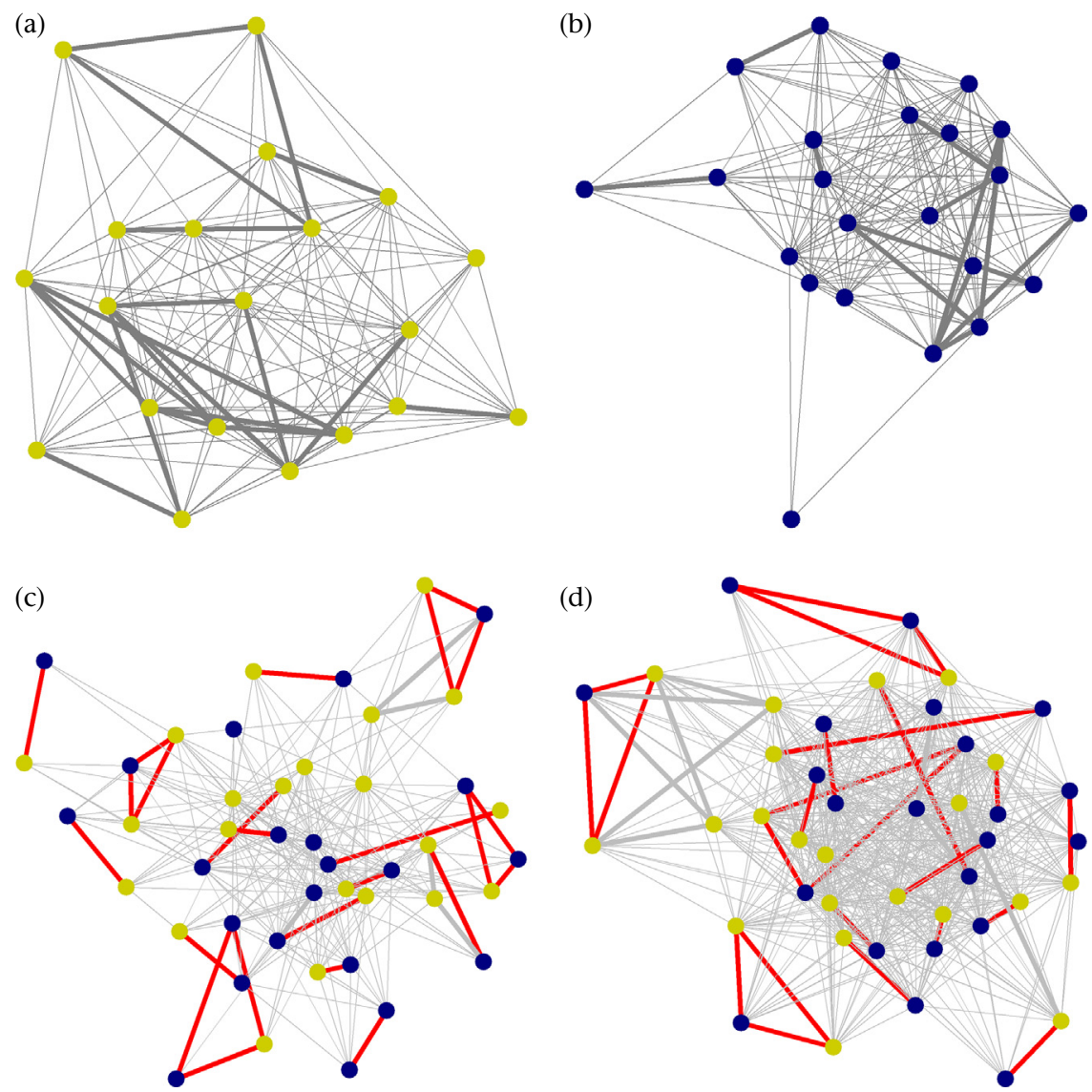

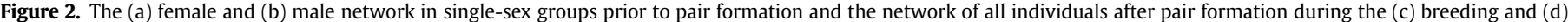

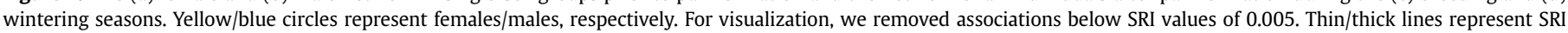

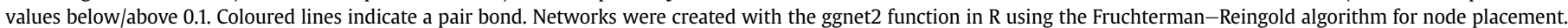



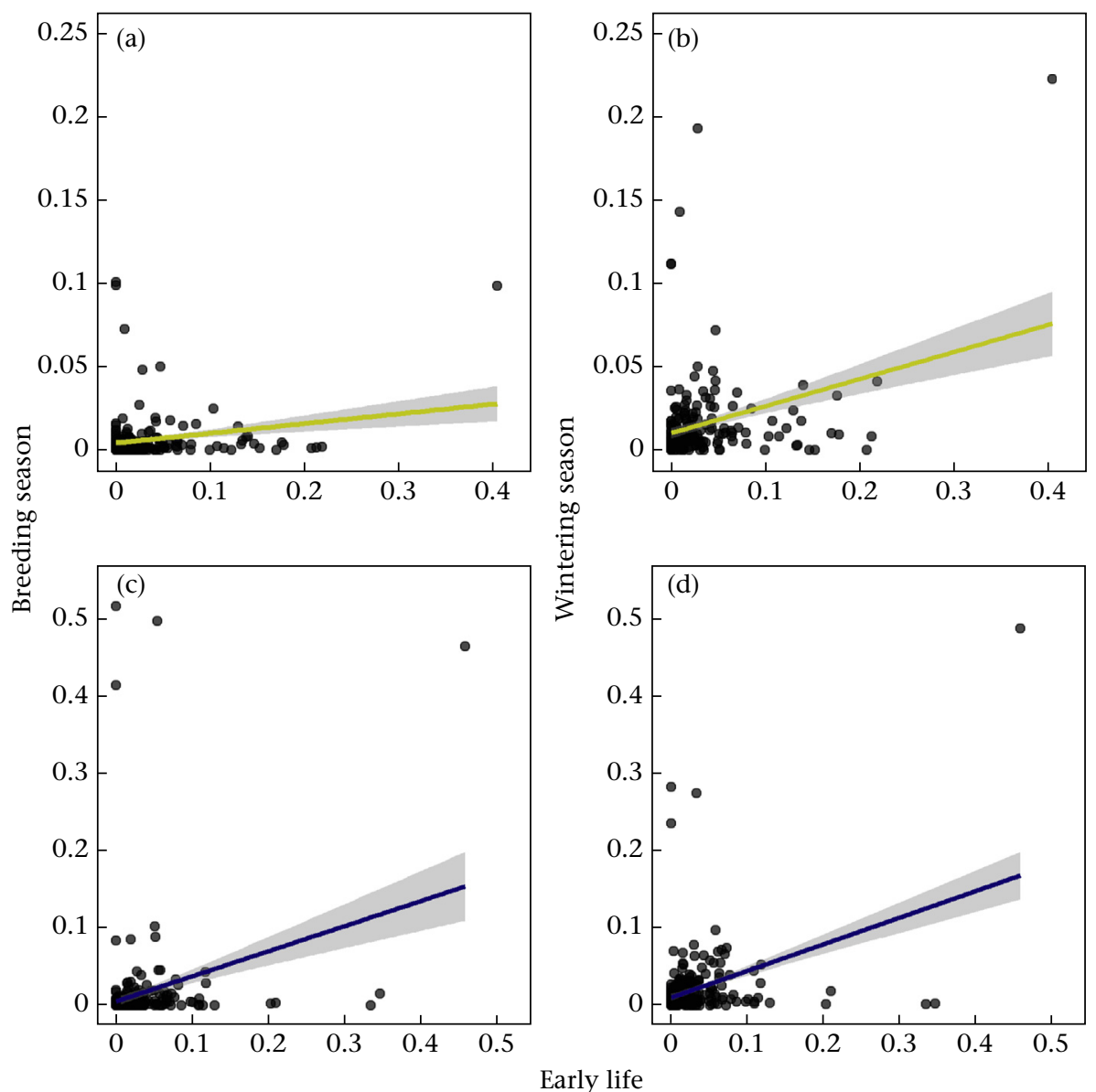

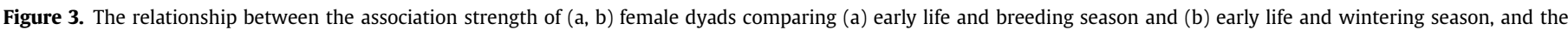

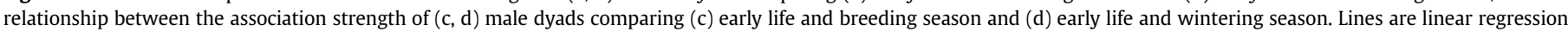
lines, including 95\% confidence bands.

-0.00026). Thus, although females and males associated more with individuals from their own familiarity and genetic relatedness groups in early life (see Kurvers et al., 2013 and Fig. A1 and A2), these factors did not drive same-sex associations after pair formation (all $P>0.1$ ).

\section{Agonistic Interactions}

We investigated two mechanisms that might drive the disappearance of social associations in females, but not males, during the breeding season. First, females may simply visit the food patches less than males during the breeding season, which would lower their opportunities for maintaining relationships. Although females visited patches less than males in the single-sex groups before pair formation ( $W=50, P<0.001$; Fig. 4a), they visited the patches as often as males in the breeding and wintering seasons (both $P>0.35$; Fig. $4 \mathrm{~b}$ and $\mathrm{c}$ ), ruling out this explanation.

A second mechanism might be that males, being generally the more dominant member of a pair, play a stronger role in determining the association members of a pair than do females, especially in the breeding season. Before pair formation, males showed a higher level of aggression than females in the single-sex groups ( $W=142, P=0.049$; Fig. 4d). Likewise, males showed a substantially higher level of aggression than females during the breeding $(W=8, P<0.001$; Fig. $4 \mathrm{e})$ and wintering seasons $(W=39$, $P<0.001$; Fig. 4f). Males displayed equal levels of aggression towards males and females in the breeding season (Wilcoxon signed- ranks test: $V=76, P=0.10$; Fig. $4 \mathrm{e}$ ) but slightly higher levels of aggression towards males than females in the wintering season $(V=50, P=0.02$; Fig. 4f). As expected, male geese displayed higher levels of aggression in the breeding than in the wintering season (Wilcoxon signed-ranks test: males only: $V=240, P<0.001$; Fig. $4 \mathrm{e}$ and $\mathrm{f}$ ). In accordance, the mean group size at patches was higher during the wintering than during the breeding season (mean group size: wintering: 2.4; breeding: 2.0; Fig. A3). Moreover, paired individuals were more tolerant of other individuals (i.e. not belonging to the pair) at a patch during the wintering season. In the breeding season, in $80 \%$ of cases when pair members were observed together on a patch, there were no other individuals present. In the wintering season, this dropped to $60 \%$ (mean number of nonpair individuals at a patch with a pair during breeding: 0.26; during wintering: 0.76; Fig. A4). This is also apparent in the network graphs showing more edges during the wintering season (Fig. $2 \mathrm{c}$ and $\mathrm{d}$ ).

\section{DISCUSSION}

Maintaining stable social associations across time and contexts can have adaptive benefits (Kohn, 2017). Yet the importance of the early life period for the formation of such long-term stable relationships has so far received little attention. Here we have shown that early life same-sex foraging associations can persist after a major life history transition, pair formation, in a monogamous and long-lived bird species. However, which associations were 
Early life
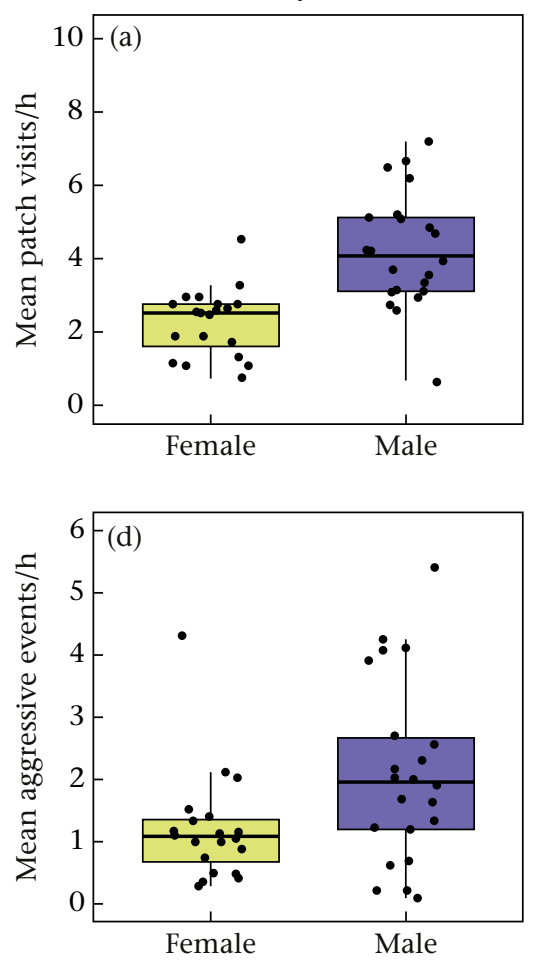

Breeding
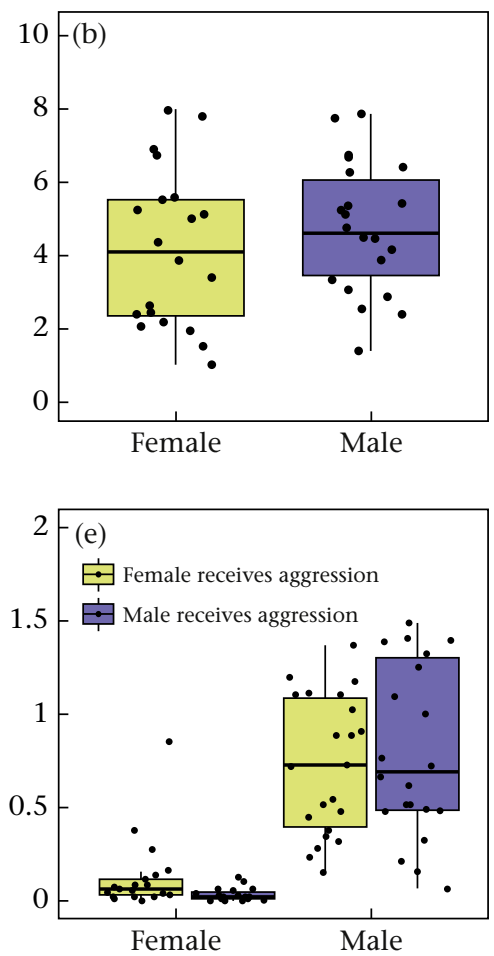

Wintering
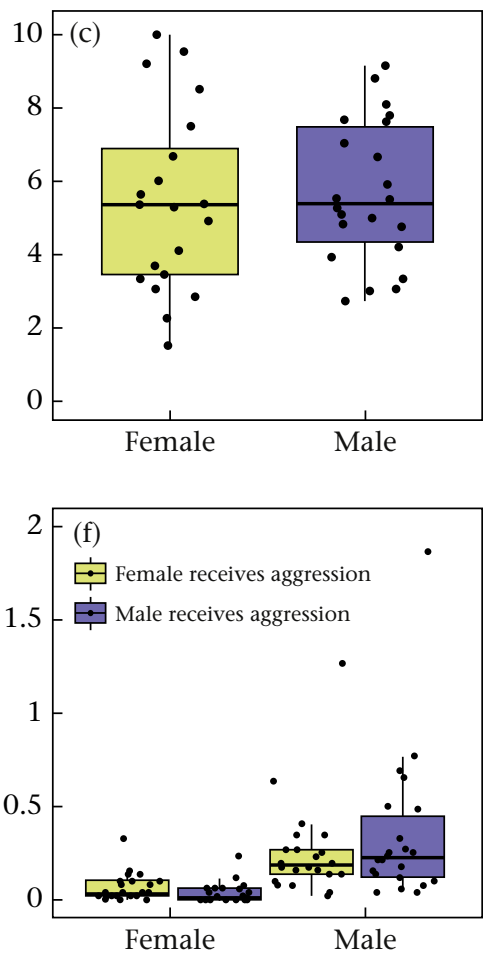

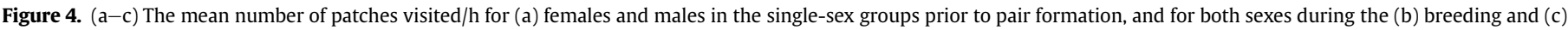

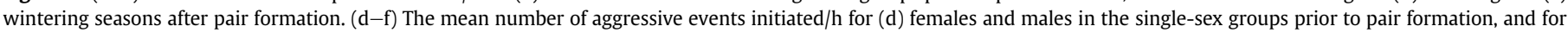

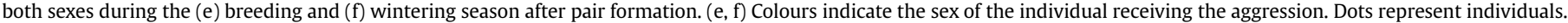
Box plots show median and interquartile ranges; whiskers show the lowest/highest values within 1.5 times the interquartile range.

maintained depended on sex and season. Early life associations in females were lost during the breeding season but resurfaced again during the subsequent wintering season. In males, the early life associations persisted across both seasons. We found no evidence of genetic relatedness or familiarity on association persistence. Elevated male aggression probably influenced the limited number of contacts outside the pair bond during the breeding season, and thereby the extent to which early life associations could be maintained, especially by females during the breeding season. Our findings extend the understanding of how social relationships develop and are maintained over different life history phases and how their importance to individuals may vary with season.

Across taxa, females are well known for maintaining long-term social relationships (Cameron et al., 2009; Carter et al., 2013; Ilany, Booms, \& Holekamp, 2015; Silk, Alberts, \& Altmann, 2003), which is commonly attributed to their reproductive strategies. In our study, males, not females, maintained their associations throughout both the breeding and wintering seasons. Benefits of social relationships in males have been observed in other species: male red-winged blackbirds, Agelaius phoeniceus, that bred close to familiar neighbours fledged more offspring (Beletsky \& Orians, 1989) and male Assamese macaques, Macaca assamensis, with stronger social associations sired more offspring (Schulke, Bhagavatula, Vigilant, \& Ostner, 2010). Males can thus clearly form, and benefit from, long-lasting social relationships.

Social relationships in males often take the form of coalitions or alliances (Connor et al., 2017; Gilby et al., 2013; Schulke et al., 2010), benefiting individuals by providing cooperation partners in agonistic interactions with conspecifics. Reduced aggression, for instance via dear-enemy effects (Temeles, 1994), can likewise be an important benefit of maintaining long-term social relationships, especially in territorial animals (Chuang, Kam, \& Bee, 2017; Jaeger, 1981; Siracusa et al., 2019). Additionally, repeated association with certain individuals can influence vigilance behaviour, with individuals showing reduced vigilance in the proximity of wellknown conspecifics (Carter et al., 2009; Kutsukake, 2006). In a monogamous prey species such as barnacle geese, in which the male spends much of its time during the breeding season on vigilance at the expense of foraging (Forslund, 1993), such benefits can be especially substantial. The expected benefits of maintaining long-term social relationships vary with ecological and social conditions (Connor et al., 2017; Kappeler, Barrett, Blumstein, \& Clutton-Brock, 2013; Maher \& Burger, 2011), and studying the social structure of both sexes in taxa with distinct space use (e.g. natal philopatry), life history (e.g. long life span), social organization (e.g. fission-fusion) and mating system (e.g. monogamy) characteristics offers us greater insight into the drivers and constraints of maintaining long-term stable associations in animal societies.

The apparent lack of social association persistence for females in the breeding season is surprising, but adds to our understanding of social flexibility by showing that the persistence of social relationships not only varies between species and individuals (Kappeler et al., 2013) but can also have sex-specific effects across seasons. Female chacma baboons, Papio hamadryas ursinus, were similarly found to vary in their social preferences depending on ecological context (Henzi, Lusseau, Weingrill, van Schaik, \& Barrett, 2009): social preferences were more pronounced when food resources were scarce, but females acted more 'gregariously' (i.e. without social preferences) when resources were plentiful. For geese, winter is a time when resources become scarce; barnacle geese, however, are highly gregarious in winter (Black et al., 2014), possibly to access social information on foraging opportunities 
(Drent \& Swierstra, 1977; Kurvers et al., 2009; Kurvers et al., 2010; but see ; Kurvers et al., 2014). Alternatively, the fluctuations in female social preferences may have been the result of the male partner unselectively excluding his partner's, but not his own, early life companions during the breeding season. The high level of aggression displayed by the males during the breeding season compared to the wintering season supports this hypothesis.

The absence of continued association with early life companions in females in the breeding season appears to contrast with previous findings. An earlier study on wild barnacle geese found that female, but not male, geese exhibited social preferences in terms of nesting proximity, with females nesting closer to familiar females (van der Jeugd et al., 2002). It is possible that nest choice offers female geese an alternative way to maintain early life social associations, circumventing the potentially controlling influence of their partner during foraging. Possibly, breeding in proximity to familiar and/or related conspecifics provides context-specific benefits that foraging together does not. Intraspecific brood parasitism and adoption are common in waterfowl (Anderholm et al., 2009a; Andersson, Åhlund, \& Waldeck, 2019; Choudhury, Jones, Black, \& Prop, 1993; Forslund \& Larsson, 1995) and breeding close to related individuals may decrease the costs, through inclusive fitness benefits, of having to care for additional offspring. Moreover, breeding in proximity could enable siblings to defend each other's nests against unrelated brood parasites. Female siblings may also actively or passively support each other in the acquisition of high-quality nest locations. Indeed, in geese, social support from family members is known to give individuals an advantage in competitive interactions, starting from an early age (Black \& Owen, 1989; Raveling et al., 2000; Scheiber et al., 2005, 2009). Lastly, neighbouring barnacle geese pairs are known to defend their nests together (Black \& Owen, 1995) and nesting closely to familiars may facilitate cooperative nest defence (Grabowska-Zhang, Sheldon, \& Hinde, 2012; Olendorf, Getty, \& Scribner, 2004). Nest predation is a major threat for geese (Drent \& Prop, 2008) that exposes the females in particular to considerable predation risk (Samelius \& Alisauskas, 2006).

Our captive study design had several important limitations compared to natural settings. First, the group size under study was relatively small compared to natural groups. In natural groups, the number of genetically related and/or familiar individuals may be substantially higher, allowing geese more opportunities to associate with these types of individuals. Second, our subjects had less space than in natural conditions. This may have led to higher levels of aggression, especially among males, and/or more and stronger associations than in more natural settings. Third, we removed the eggs of breeding females to avoid the undesired hatching of more experimental animals. This may have increased aggression and may have had repercussions for social relationships. Almost all pair bonds, however, remained intact until the next wintering season, suggesting that egg removal did not cause major disruption of pair bonds.

Taken together, our findings suggest that different types of social associations may be beneficial in different contexts and that the early life period can be a crucial time for the formation of these associations. The next step is to disentangle whether individuals actively choose to (re)associate with earlier companions depending on season- and context-dependent benefits, or whether the observed fluctuations in persistence of social associations are an emergent property following relatively simple season-dependent social processes, such as heightened aggression. The first scenario may have important implications for our understanding of the cognitive abilities of animals. Notably, Scheiber, Hohnstein, Kotrschal, and Weiß (2011) found that 6-week-old juvenile greylag geese can already discriminate between two of their siblings, showing that individual level recognition is already present from an early age. Our findings here suggest that geese may be able to keep track of multiple types of relationships in a large fission-fusion society, despite extended breaks, supporting similar observations in wild barnacle geese (Black \& Owen, 1995), and that they can re-evaluate the benefits of these relationships depending on context. Given the strong evidence for birthplace-independent long-term kin discrimination in both migrating and captive barnacle geese (Anderholm et al., 2009b; Kurvers et al., 2013; van der Jeugd et al., 2002), this level of cognitive ability is certainly feasible and makes the long-lived barnacle goose an interesting study system to further examine such mechanisms. Complex social patterns can be driven by cognitive ability, but also emerge from relatively simple processes (Kappeler, 2019), such as site fidelity combined with season- and sex-dependent aggression. Unravelling how these mechanisms underlie social complexity in a diversity of social systems will be central to our understanding of the evolution of animal societies.

\section{Data availability}

The raw social association observations, the matrices containing the SRI values per sex per season, the matrices containing the familiarity and genetic relatedness data per sex and the raw aggression data are uploaded on the Open Science Framework (link).

\section{Acknowledgments}

We thank Bart van Lith from the Netherlands Institute of Ecology for looking after the birds, and Chantal Althuizen and Jan Baar for help during the social network observations. We thank Herbert Prins, Ron Ydenberg and Sip van Wieren for their guidance on the experimental design. We thank the Faunafonds and the Koninklijke Nederlands Jagers Vereniging (KNJV) for financial support, and Bart Nolet and Marcel Klaassen for facilitating the animal-holding facilities. We thank Rudy Jonker for blood sampling; Henk van der Jeugd for sexing the geese; and Rudy Jonker, Robert Kraus, Richard Crooijmans, Martien Groenen, Qiong Zhang and Bert Dibbits for the genetic lab work. Finally, we thank Deborah Ain, Mike Webster and two anonymous referees for their helpful comments on the manuscript. D.R.F. was funded by the Max Planck Society, the Deutsche Forschungsgemeinschaft (DFG grant FA 1402/4-1), and the DFG Centre of Excellence 2117 'Centre for the Advanced Study of Collective Behaviour' (ID: 422037984). L.S. was funded by a postdoc fellowship of the Alexander von Humboldt Stiftung (Ref 3.3-NLD-1192631-HFST-P).

\section{References}

Alexander, R. D. (1974). The evolution of social behavior. Annual Review of Ecology and Systematics, 5(1), 325-383. https://doi.org/10.1146/ annurev.es.05.110174.001545.

Anderholm, S., Marshall, R. C., van der Jeugd, H. P., Waldeck, P., Larsson, K., \& Andersson, M. (2009a). Nest parasitism in the barnacle goose: Evidence from protein fingerprinting and microsatellites. Animal Behaviour, 78(1), 167-174. https://doi.org/10.1016/j.anbehav.2009.04.011.

Anderholm, S., Waldeck, P., Van der Jeugd, H. P., Marshall, R. C., Larsson, K., \& Andersson, M. (2009b). Colony kin structure and host-parasite relatedness in the barnacle goose. Molecular Ecology, 18(23), 4955-4963. https://doi.org/ 10.1111/j.1365-294X.2009.04397.x.

Andersson, M., Åhlund, M., \& Waldeck, P. (2019). Brood parasitism, relatedness and sociality: A kinship role in female reproductive tactics. Biological Reviews, 94(1), 307-327.

Bejder, L., Fletcher, D., \& Brager, S. (1998). A method for testing association patterns of social animals. Animal Behaviour, 56, 719-725.

Beletsky, L. D., \& Orians, G. H. (1989). Familiar neighbors enhance breeding success in birds. Proceedings of the National Academy of Sciences, 86(20), 7933-7936. https://doi.org/10.1073/pnas.86.20.7933. 
Black, J. M. (2001). Fitness consequences of long-term pair bonds in barnacle geese: Monogamy in the extreme. Behavioral Ecology, 12(5), 640-645. https://doi.org/ 10.1093/beheco/12.5.640.

Black, J. M., Choudhury, S., \& Owen, M. (1996). Do barnacle geese benefit from lifelong monogamy? In J. M. Black (Ed.), Partnerships in birds: the study of monogamy (pp. 91-117). Oxford, U.K.: Oxford University Press.

Black, J. M., \& Owen, M. (1989). Parent offspring relationships in wintering barnacle geese. Animal Behaviour, 37, 187-198. https://doi.org/10.1016/0003-3472(89) 90109-7.

Black, J. M., \& Owen, M. (1995). Reproductive performance and assortative pairing in relation to age in Barnacle geese. Journal of Animal Ecology, 64(2), 234-244. https://doi.org/10.2307/5758.

Black, J. M., Prop, J., \& Larsson, K. (2014). The barnacle goose. London, U.K Bloomsbury Publishing.

Blumstein, D. T., Wey, T. W., \& Tang, K. (2009). A test of the social cohesion hypothesis: Interactive female marmots remain at home. Proceedings of the Roya Society B: Biological Sciences, 276(1669), 3007-3012. https://doi.org/10.1098 rspb.2009.0703.

Cameron, E. Z., Setsaas, T. H., \& Linklater, W. L. (2009). Social bonds between unrelated females increase reproductive success in feral horses. Proceedings of the National Academy of Sciences of the United States of America, 106(33), 13850-13853. https://doi.org/10.1073/pnas.0900639106.

Carter, K. D., Brand, R., Carter, J. K., Shorrocks, B., \& Goldizen, A. W. (2013). Socia networks, long-term associations and age-related sociability of wild giraffes. Animal Behaviour, 86(5), 901-910. https://doi.org/10.1016 j.anbehav.2013.08.002.

Carter, A. J., Macdonald, S. L., Thomson, V. A., \& Goldizen, A. W. (2009). Structured association patterns and their energetic benefits in female eastern grey kangaroos, Macropus giganteus. Animal Behaviour, 77(4), 839-846.

Choudhury, S., \& Black, J. M. (1993). Mate selection behavior and sampling strategies in geese. Animal Behaviour, 46(4), 747-757.

Choudhury, S., \& Black, J. M. (1994). Barnacle geese preferentially pair with familiar associates from early-life. Animal Behaviour, 48(1), 81-88.

Choudhury, S., Jones, C. S., Black, J. M., \& Prop, J. (1993). Adoption of young and intraspecific nest parasitism in barnacle geese. Condor: Ornithological Applications, 95(4), 860-868.

Chuang, M.-F., Kam, Y.-C., \& Bee, M. A. (2017). Territorial olive frogs display lowe aggression towards neighbours than strangers based on individual vocal signatures. Animal Behaviour, 123, 217-228.

Connor, R. C., Cioffi, W. R., Randic, S., Allen, S. J., Watson-Capps, J., \& Krutzen, M (2017). Male alliance behaviour and mating access varies with habitat in dolphin social network. Scientific Reports, 7, 46354. https://doi.org/10.1038/ srep46354.

Croft, D. P., James, R., \& Krause, J. (2008). Exploring animal social networks. Princeton, NJ: Princeton University Press.

Drent, R. H., \& Prop, J. (2008). Barnacle goose Branta leucopsis survey on nordenskiöldkysten, west Spitsbergen 1975-2007: Breeding in relation to carrying capacity and predator impact. Circumpolar Studies, 4, 59-83.

Drent, R. H., \& Swierstra, P. (1977). Goose flocks and food finding: Field experiments with barnacle geese in winter. Wildfowl, 28, 15-20.

Farine, D. R. (2013). Animal social network inference and permutations for ecologists in R using asnipe. Methods in Ecology and Evolution, 4(12), 1187-1194.

Farine, D. R. (2017). A guide to null models for animal social network analysis Methods in Ecology and Evolution, 8(10), 1309-1320. https://doi.org/10.1111/ 2041-210x.12772.

Farine, D. R., \& Whitehead, H. (2015). Constructing, conducting and interpreting animal social network analysis. Journal of Animal Ecology, 84(5), 1144-1163.

Firth, J. A., \& Sheldon, B. C. (2016). Social carry-over effects underpin transseasonally linked structure in a wild bird population. Ecology Letters, 19(11) 1324-1332.

Forslund, P. (1993). Vigilance in relation to brood size and predator abundance in the barnacle goose Branta leucopsis. Animal Behaviour, 45(5), 965-973.

Forslund, P., \& Larsson, K. (1995). Intraspecific nest parasitism in the barnacle goose: Behavioural tactics of parasites and hosts. Animal Behaviour, 50(2), 509-517.

Franks, D. W., Ruxton, G. D., \& James, R. (2010). Sampling animal association networks with the gambit of the group. Behavioral Ecology and Sociobiology, 64(3) 493-503. https://doi.org/10.1007/s00265-009-0865-8.

Frigerio, D., Weiss, B., \& Kotrschal, K. (2001). Spatial proximity among adult siblings in greylag geese (Anser anser): Evidence for female bonding? Acta Ethologica, $121-125$

Gilby, I. C., Brent, L. J. N., Wroblewski, E. E., Rudicell, R. S., Hahn, B. H., Goodall, J., et al. (2013). Fitness benefits of coalitionary aggression in male chimpanzees. Behavioral Ecology and Sociobiology, 67(3), 373-381. https://doi.org/10.1007/ s00265-012-1457-6.

Ginsberg, J. R., \& Young, T. P. (1992). Measuring association between individuals or groups in behavioral studies. Animal Behaviour, 44(2), 377-379. https://oi.org 10.1016/0003-3472(92)90042-8.

Grabowska-Zhang, A., Sheldon, B., \& Hinde, C. (2012). Long-term familiarity promotes joining in neighbour nest defence. Biology Letters, 8(4), 544-546.

Griffiths, S. W., Brockmark, S., Höjesjö, J., \& Johnsson, J. (2004). Coping with divided attention: The advantage of familiarity. Proceedings of the Royal Society. Series B: Biological Sciences, 271(1540), 695-699.

Henzi, S. P., Lusseau, D., Weingrill, T., van Schaik, C. P., \& Barrett, L. (2009). Cyclicity in the structure of female baboon social networks. Behavioral Ecology and Sociobiology, 63(7), 1015-1021. https://doi.org/10.1007/s00265-009-0720-y.
Hoppitt, W. J., \& Farine, D. R. (2018). Association indices for quantifying social relationships: How to deal with missing observations of individuals or groups. Animal Behaviour, 136, 227-238.

Ilany, A., Booms, A. S., \& Holekamp, K. E. (2015). Topological effects of network structure on long-term social network dynamics in a wild mammal. Ecology Letters, 18(7), 687-695.

Jaeger, R. G. (1981). Dear enemy recognition and the costs of aggression between salamanders. American Naturalist, 117(6), 962-974.

Jonker, R. M., Zhang, Q., Van Hooft, P., Loonen, M. J., Van der Jeugd, H. P., Crooijmans, R. P., et al. (2012). The development of a genome wide SNP set for the Barnacle goose Branta leucopsis. PloS One, 7(7), e38412. https://doi.org/ 10.1371/journal.pone.0038412.

Kappeler, P. M. (2019). A framework for studying social complexity. Behavioral Ecology and Sociobiology, 73(1), 13. https://doi.org/10.1007/s00265-0182601-8.

Kappeler, P. M., Barrett, L., Blumstein, D. T., \& Clutton-Brock, T. H. (2013). Constraints and flexibility in mammalian social behaviour: Introduction and synthesis. Philosophical Transactions of the Royal Society B: Biological Sciences, 368(1618), 20120337. https://doi.org/10.1098/rstb.2012.0337.

Kerth, G., Perony, N., \& Schweitzer, F. (2011). Bats are able to maintain long-term social relationships despite the high fission-fusion dynamics of their groups. Proceedings of the Royal Society B, 278(1719), 2761-2767. https://doi.org/ $10.1098 / \mathrm{rspb} .2010 .2718$

Kohn, G. M. (2017). Friends give benefits: Autumn social familiarity preferences predict reproductive output. Animal Behaviour, 132, 201-208.

Krackhardt, D. (1988). Predicting with networks: Nonparametric multiple regression analysis of dyadic data. Social Networks, 10, 359-381.

Krause, J., \& Ruxton, G. (2002). Living in Groups. Oxford: Oxford University Press.

Kraus, R. H. S., Kerstens, H., Van Hooft, P., Crooijmans, R., Van Der Poel, J., Elmberg, J., et al. (2011). Genome wide SNP discovery, analysis and evaluation in mallard (Anas platyrhynchos). BMC Genomics, 12(1), 150.

Kurvers, R. H. J. M., Adamczyk, V. M. A. P., Kraus, R. H. S., Hoffman, J. I., van Wieren, S. E., van der Jeugd, H. P., et al. (2013). Contrasting context dependence of familiarity and kinship in animal social networks. Animal Behaviour, 86(5), 993-1001. https://doi.org/10.1016/j.anbehav.2013.09.001.

Kurvers, R. H. J. M., Eijkelenkamp, B., van Oers, K., van Lith, B., van Wieren, S. E., Ydenberg, R. C., et al. (2009). Personality differences explain leadership in barnacle geese. Animal Behaviour, 78(2), 447-453.

Kurvers, R. H. J. M., Prins, H. H. T., van Wieren, S. E., van Oers, K., Nolet, B. A., \& Ydenberg, R. C. (2010). The effect of personality on social foraging: Shy barnacle geese scrounge more. Proceedings of the Royal Society B: Biological Sciences, 277(1681), 601-608

Kurvers, R. H., Straates, K., Ydenberg, R. C., van Wieren, S. E., Swierstra, P. S., \& Prins, H. H. (2014). Social information use by barnacle geese Branta leucopsis, an experiment revisited. Ardea, 102(2), 173-181.

Kutsukake, N. (2006). The context and quality of social relationships affect vigilance behaviour in wild chimpanzees. Ethology, 112(6), 581-591.

Langenhof, M. R., \& Komdeur, J. (2018). Why and how the early-life environment affects development of coping behaviours. Behavioral Ecology and Sociobiology, 72(3), 34. https://doi.org/10.1007/s00265-018-2452-3.

Leris, I., \& Reader, S. M. (2016). Age and early social environment influence guppy social learning propensities. Animal Behaviour, 120, 11-19. https://doi.org/ 10.1016/j.anbehav.2016.07.012.

Lindström, J. (1999). Early development and fitness in birds and mammals. Trends in Ecology \& Evolution, 14(9), 343-348. https://doi.org/10.1016/S0169-5347(99) 01639-0.

Linklater, W. L., \& Cameron, E. Z. (2009). Social dispersal but with philopatry reveals incest avoidance in a polygynous ungulate. Animal Behaviour, 77(5), 1085-1093.

Maher, C. R., \& Burger, J. R. (2011). Intraspecific variation in space use, group size, and mating systems of caviomorph rodents. Journal of Mammalogy, 92(1), 54-64.

Milligan, B. G. (2003). Maximum-likelihood estimation of relatedness. Genetics, 163(3), 1153-1167.

Mitani, J. C. (2009). Male chimpanzees form enduring and equitable social bonds. Animal Behaviour, 77(3), 633-640. https://doi.org/10.1016/ j.anbehav.2008.11.021.

Oksanen, J., Blanchet, G., Friendly, M., Kindt, R., Legendre, P., McGlinn, D., et al. (2019). vegan: Community Ecology Package. R package version 2, 5-4.

Olendorf, R., Getty, T., \& Scribner, K. (2004). Cooperative nest defence in red-winged blackbirds: Reciprocal altruism, kinship or by-product mutualism? Proceedings of the Royal Society. Series B: Biological Sciences, 271(1535), 177-182.

Owen, M., Black, J. M., \& Liber, H. (1988). Pair bond duration and timing of its formation in barnacle geese (Branta leucopsis). In M. W. Weller (Ed.), Waterfowl in winter (pp. 23-38). Minneapolis, MN: University of Minnesota Press.

Owen, M., \& Wells, R. (1979). Territorial behaviour in breeding geese-a reexamination of Ryder's hypothesis. Wildfowl, 30(30), 20-26.

Percival, S. M. (1991). The population-structure of Greenland barnacle geese Brantaleucopsis on the wintering Grounds on Islay. Ibis, 133(4), 357-364.

Raveling, D. G., Sedinger, J. S., \& Johnson, D. S. (2000). Reproductive success and survival in relation to experience during the first two years in Canada geese. Condor: Ornithological Applications, 102(4), 941-945.

Robertson, G. J., \& Cooke, F. (1999). Winter philopatry in migratory waterfowl. Auk: Ornithological Advances, 116(1), 20-34. 
Sachser, N., Dürschlag, M., \& Hirzel, D. (1998). Social relationships and the management of stress. Psychoneuroendocrinology, 23(8), 891-904. https://doi.org/ 10.1016/S0306-4530(98)00059-6.

Samelius, G., \& Alisauskas, R. T. (2006). Sex-biased costs in nest defence behaviours by lesser snow geese (Chen caerulescens): Consequences of parental roles? Behavioral Ecology and Sociobiology, 59(6), 805-810.

Scheiber, I. B. R., Hohnstein, A., Kotrschal, K., \& Weiß, B. M. (2011). Juvenile greylag geese (Anser anser) discriminate between individual siblings. PloS One, 6(8), e22853. https://doi.org/10.1371/journal.pone.0022853.

Scheiber, I. B. R., Kotrschal, K., \& Weiss, B. M. (2009). Benefits of family reunions: Social support in secondary greylag goose families. Hormones and Behavior, 55(1), 133-138. https://doi.org/10.1016/j.yhbeh.2008.09.006.

Scheiber, I. B. R., Weiss, B. M., Frigerio, D., \& Kotrschal, K. (2005). Active and passive social support in families of greylag geese (Anser anser). Behaviour, 142, 1535-1557. https://doi.org/10.1163/156853905774831873.

Schulke, O., Bhagavatula, J., Vigilant, L., \& Ostner, J. (2010). Social bonds enhance reproductive success in male macaques. Current Biology, 20(24), 2207-2210. https://doi.org/10.1016/j.cub.2010.10.058.

Shizuka, D., Chaine, A. S., Anderson, J., Johnson, O., Laursen, I. M., \& Lyon, B. E. (2014). Across-year social stability shapes network structure in wintering migrant sparrows. Ecology Letters, 17(8), 998-1007.

Silk, J. B. (2007). Social components of fitness in primate groups. Science, 317(5843), 1347-1351.

Silk, J. B., Alberts, S. C., \& Altmann, J. (2003). Social bonds of female baboons enhance infant survival. Science, 302(5648), 1231-1234. https://doi.org/10.1126/ science.1088580.

Silk, J. B., Beehner, J. C., Bergman, T. J., Crockford, C., Engh, A. L., Moscovice, L. R., et al. (2009). The benefits of social capital: Close social bonds among female baboons enhance offspring survival. Proceedings of the Royal Society B: Biological Sciences, 276(1670), 3099-3104. https://doi.org/10.1098/rspb.2009.0681.

Silk, J. B., Beehner, J. C., Bergman, T. J., Crockford, C., Engh, A. L., Moscovice, L. R., et al. (2010). Strong and consistent social bonds enhance the Longevity of female baboons. Current Biology, 20(15), 1359-1361. https://doi.org/10.1016/j.cub.2010.05.067.

Siracusa, E. R., Wilson, D. R., Studd, E. K. Boutin, S., Humphries, M. M., Dantzer, B., et al. (2019). North American red squirrels mitigate costs of territory defence through social plasticity. Animal Behaviour, 151, 29-42.

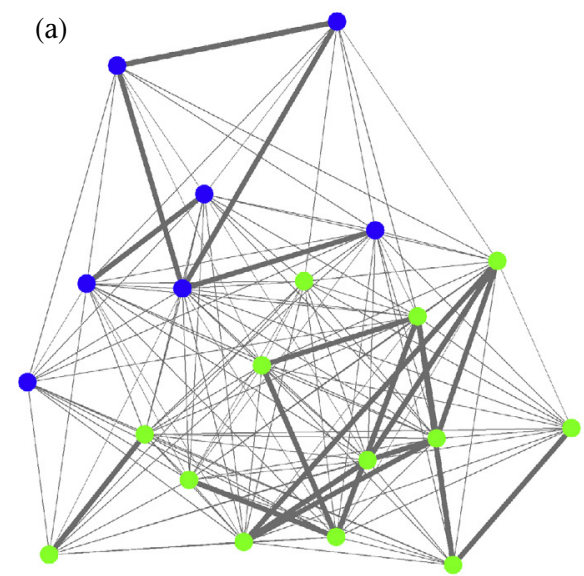

(b)

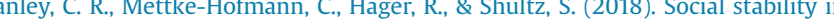
stability alongside seasonal flexibility. Animal Behaviour, 136, 175-184.

Stanton, M. A., \& Mann, J. (2012). Early social networks predict survival in wild bottlenose dolphins. PloS One, 7(10), e47508.

Szipl, G., Depenau, M., Kotrschal, K., Hemetsberger, J., \& Frigerio, D. (2019). Costs and benefits of social connectivity in juvenile Greylag geese. Scientific Reports, 9(1), 12839. https://doi.org/10.1038/s41598-019-49293-9.

Temeles, E. J. (1994). The role of neighbours in territorial systems: When are they 'dear enemies'? Animal Behaviour, 47(2), 339-350.

van der Jeugd, H. P. (2001). Large barnacle goose males can overcome the socia costs of natal dispersal. Behavioral Ecology, 12(3), 275-282.

van der Jeugd, H. P., \& Blaakmeer, K. B. (2001). Teenage love: The importance of trial liaisons, subadult plumage and early pairing in barnacle geese. Animal Behaviour, 62, 1075-1083.

van der Jeugd, H. P., van der Veen, I. T., \& Larsson, K. (2002). Kin clustering in barnacle geese: Familiarity or phenotype matching? Behavioral Ecology, 13(6), 786-790. https://doi.org/10.1093/beheco/13.6.786.

Wang, J. L. (2011). COANCESTRY: A program for simulating, estimating and analysing relatedness and inbreeding coefficients. Molecular Ecology Resources, 11(1), 141-145. https://doi.org/10.1111/j.1755-0998.2010.02885.x.

Whitehead, H. (2008). Analyzing animal societies: Quantative methods for vertebrate social analysis. Chicago, IL: University of Chicago Press.

Ydenberg, R. C., Giraldeau, L. A., \& Falls, J. B. (1988). Neighbours, strangers, and the asymmetric war of attrition. Animal Behaviour, 36(2), 343-347. https://doi.org 10.1016/S0003-3472(88)80004-6.

Zeus, V. M., Reusch, C., \& Kerth, G. (2018). Long-term roosting data reveal a unimodular social network in large fission-fusion society of the colony-living Natterer's bat (Myotis nattereri). Behavioral Ecology and Sociobiology, 72(6), 99 https://doi.org/10.1007/s00265-018-2516-4.

\section{Appendix}
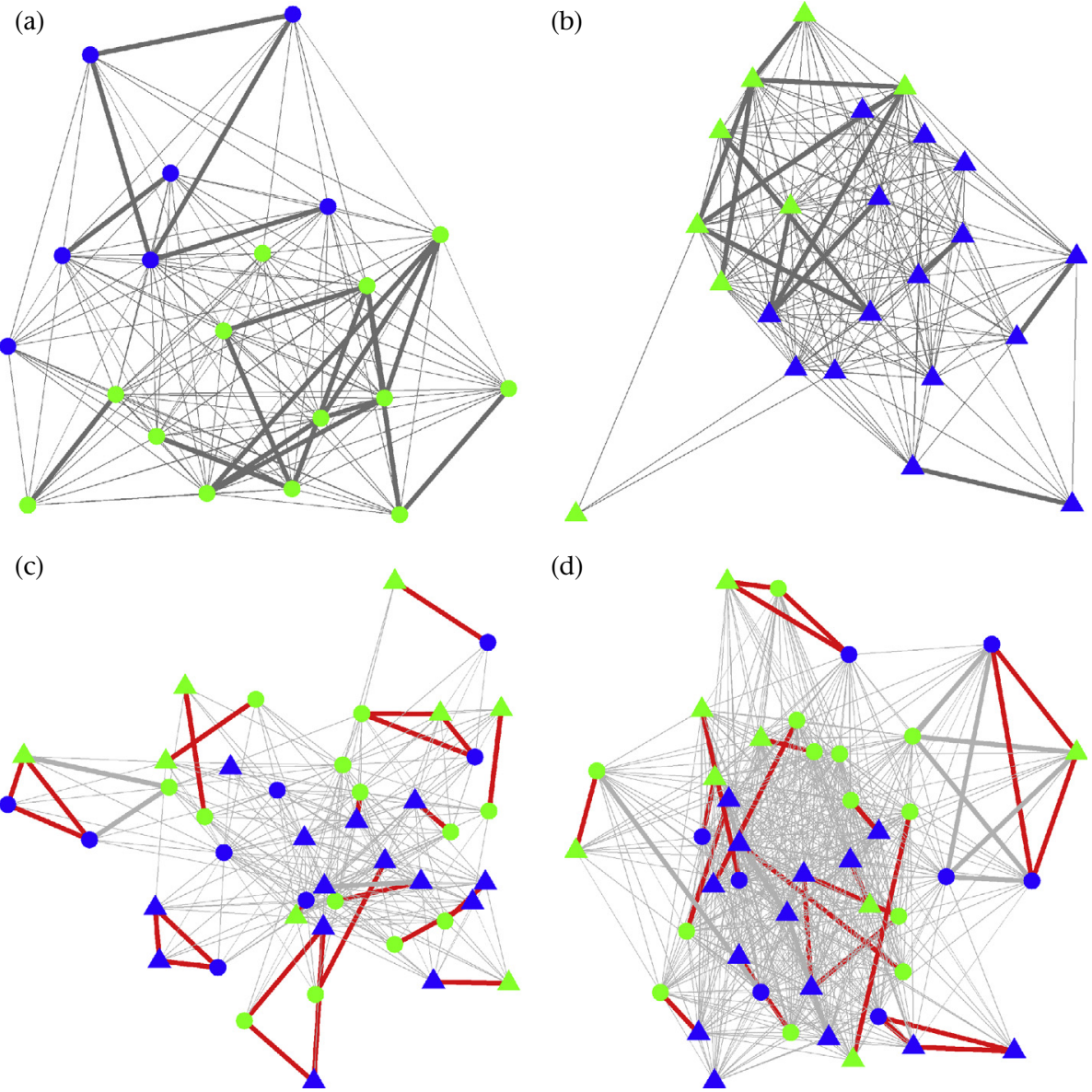

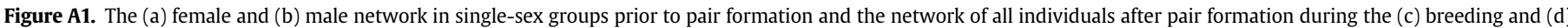

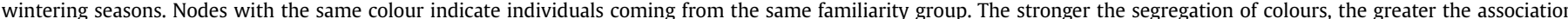
between individuals of the same familiarity group. Circles represent females and triangles males. 

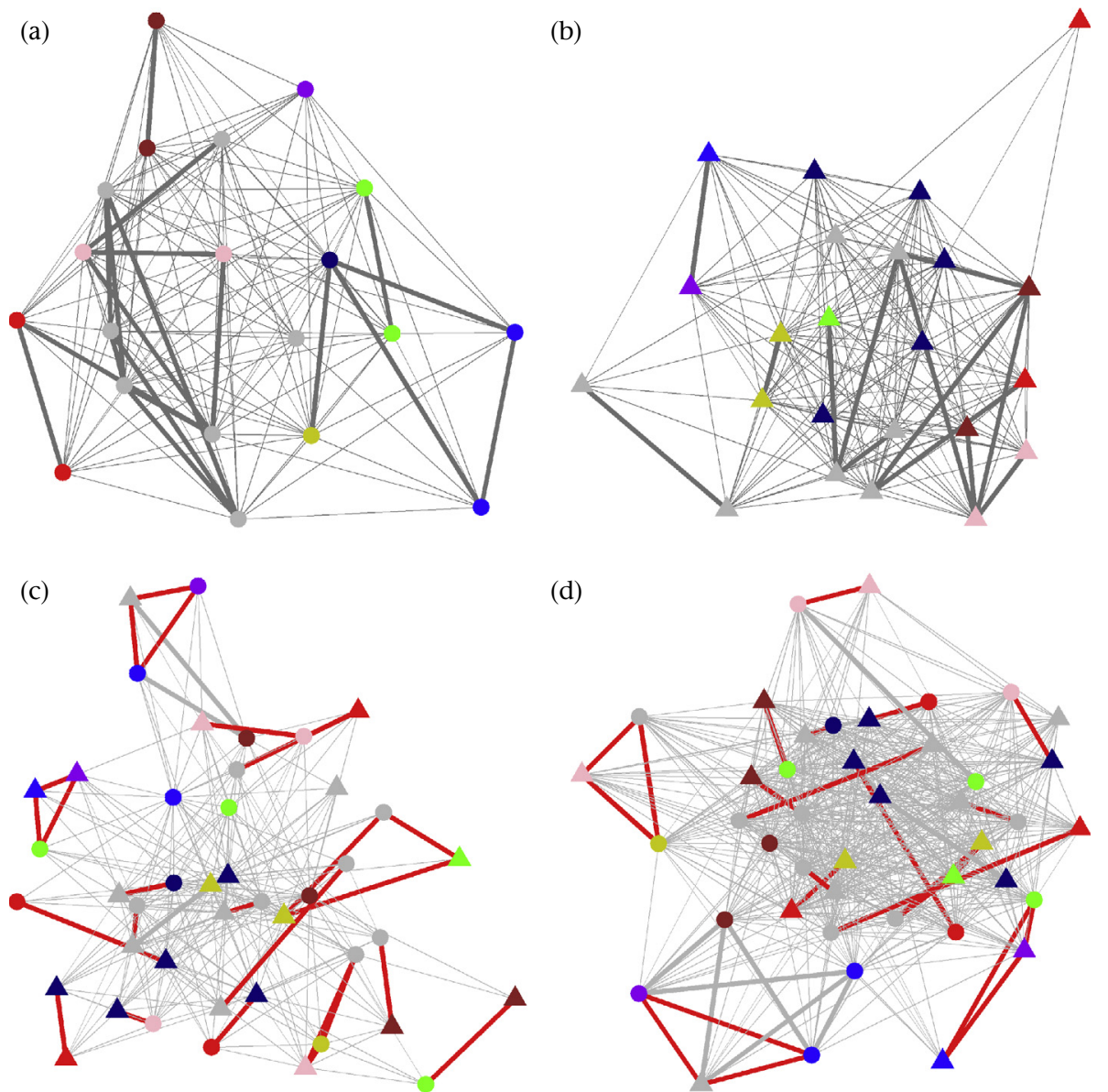

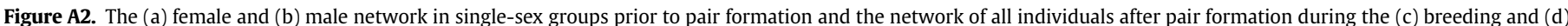

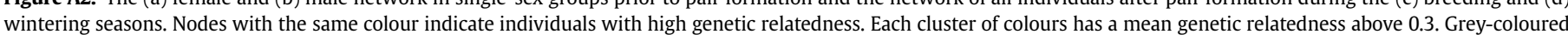
nodes represent individuals not sharing a high genetic relatedness with any individual in the population. The stronger the segregation of colours, the greater the association between individuals of the same genetic relatedness group. Circles represent females and triangles males. 

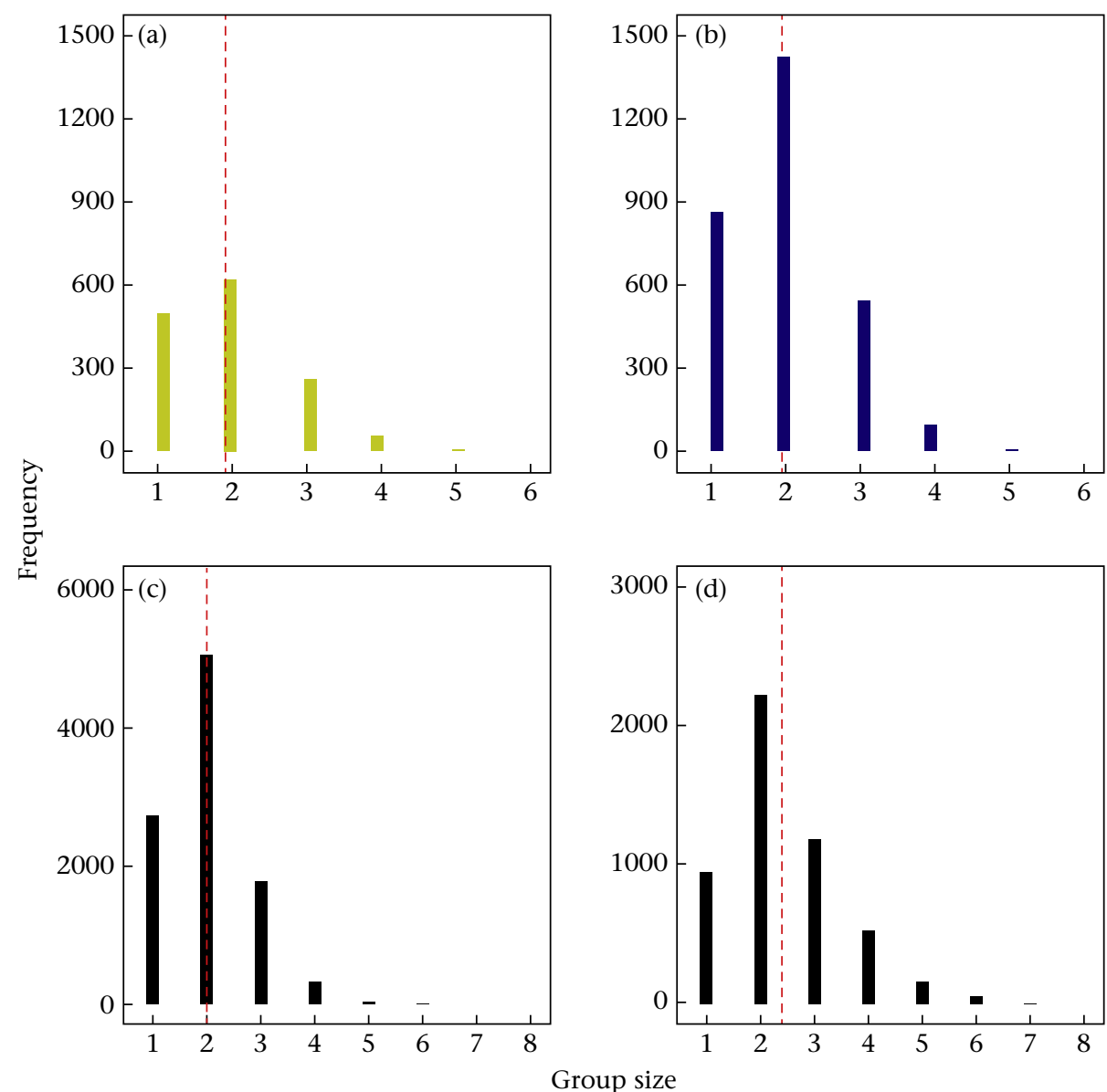

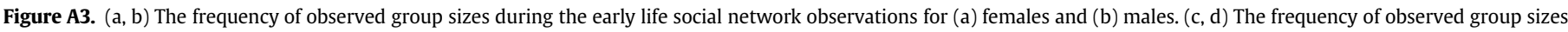

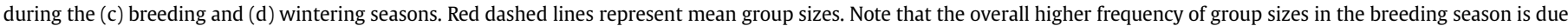
to more observation days ( $N=25$ days) than during the wintering season ( $N=13$ days). 


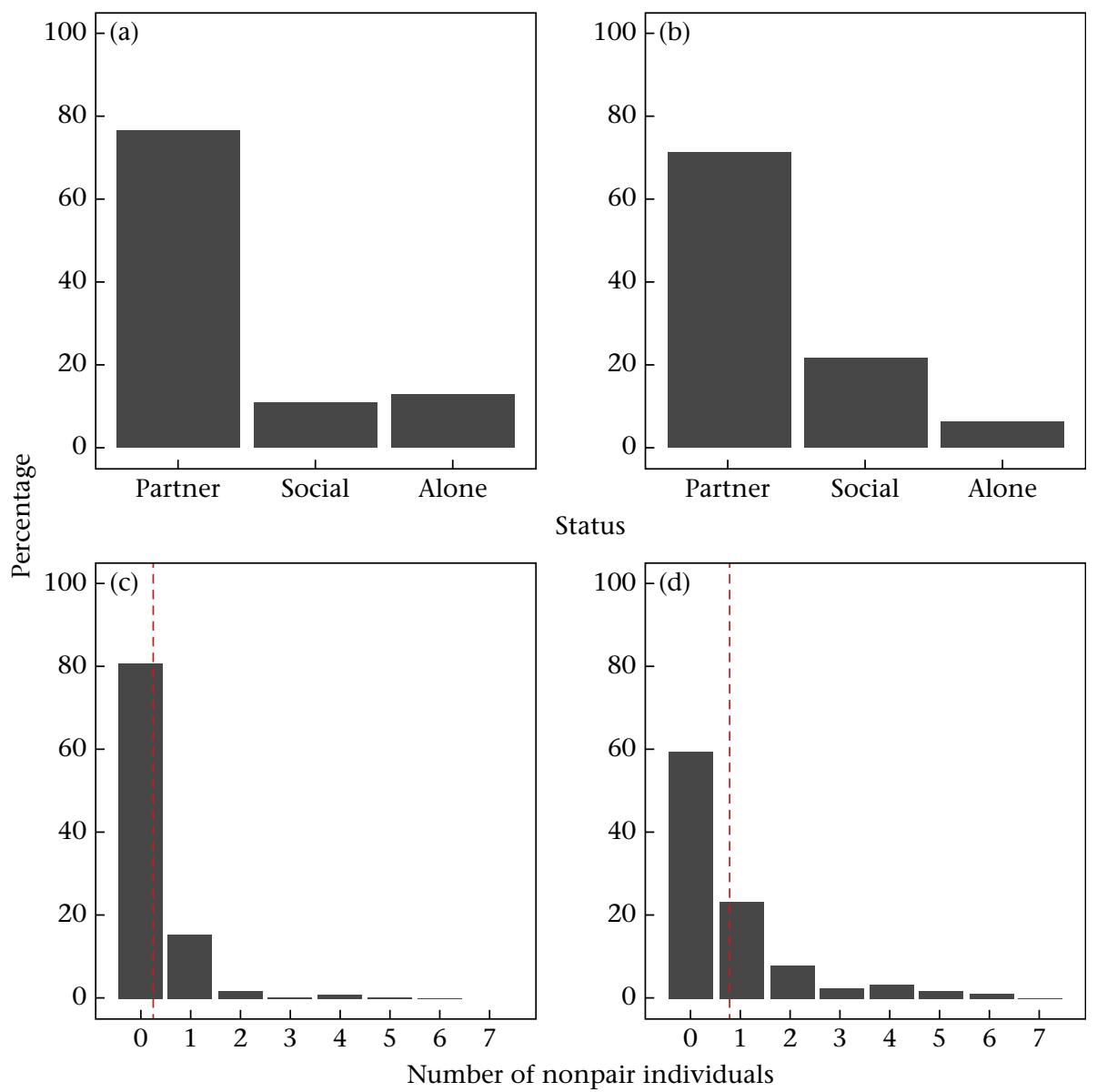

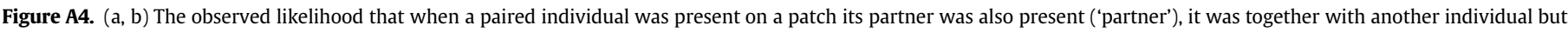

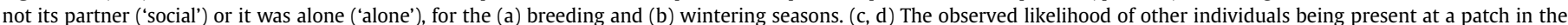
presence of a pair during the (c) breeding and (d) wintering seasons. Red dashed lines represent the average number of nonpaired geese present with a pair. 